
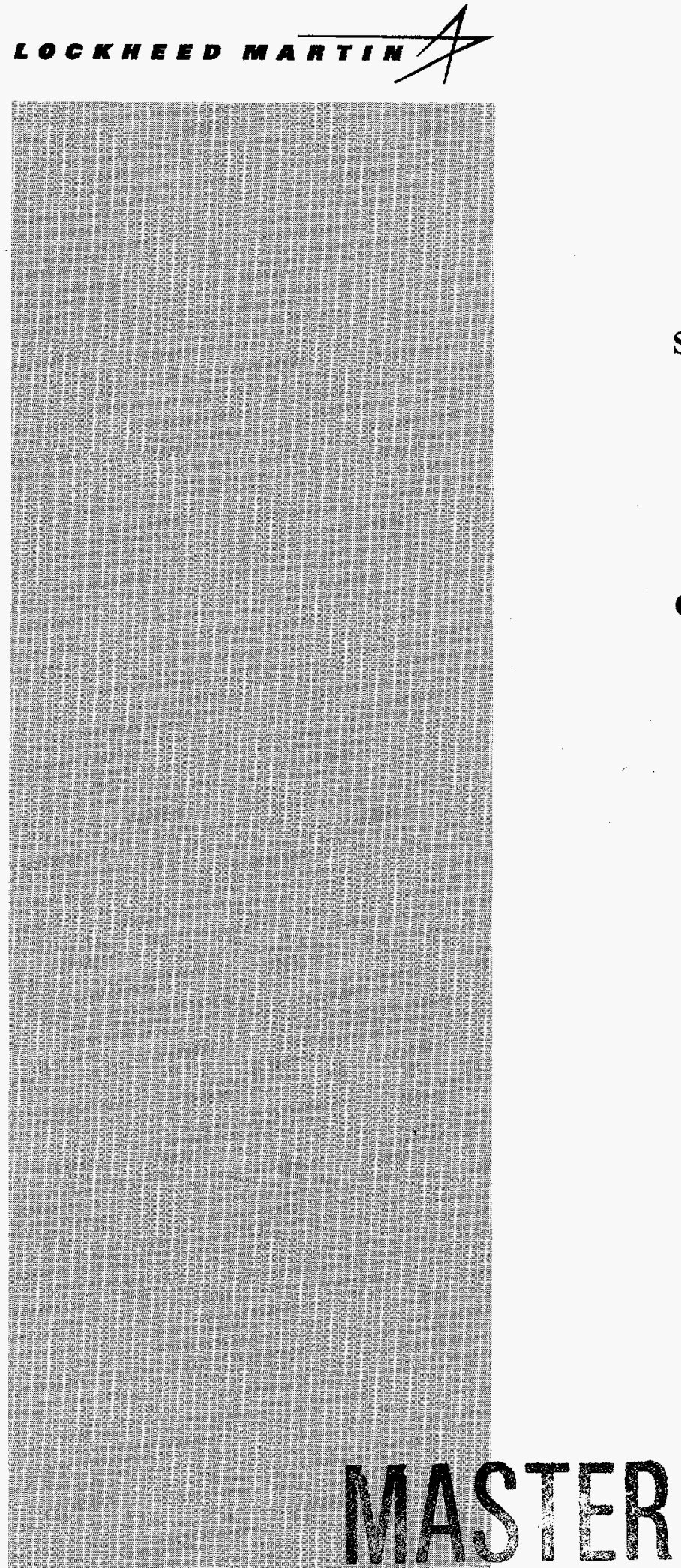

WANAGED BY

LOCKHEED WARTIN ENEREY SYSTEMS, 110.

FOR THE UNITED STATES

DEPARTUENT OFENERGY
Y/EN-5491

\section{REGEIVED}

\section{JAN O 31997 OSTI}

Shake Table Testing of Structural Clay Tile Infilled Frames

Prepared for the

Center for Natural Phenomena Engineering

March 8, 1996

For Presentation at the

1996 North American Masonry Conference South Bend, Indiana

Oak Ridge Y-12 Plant

Oak Ridge, Tennessee 37831 managed by

Lockheed Martin Energy Systems, Inc. for the

U.S. DEPARTMENT OF ENERGY under contract DE-AC05-84OR21400 


\section{DISCLAIMER}

This report was prepared as an account of work sponsored by an agency of the United States Government. Neither the United States Government nor any agency thereof, nor any of their employees, makes any warranty, express or implied, or assumes any legal liability or responsibility for the accuracy, completeness, or usefulness of any information, apparatus, product, or process disclosed, or represents that its use would not infringe privately owned rights. Reference herein to any specific commercial product, process, or service by trade name, trademark, manufacturer, or otherwise, does not necessarily constitute or imply its endorsement, recommendation, or favoring by the United States Government or any agency thereof. The views and opinions of authors expressed herein do not necessarily state or reflect those of the United States Government or any agency thereof.

\section{COPYRIGHT NOTICE}

The submitted manuscript has been authored by a contractor of the U.S. Government under contract DE-AC05-84OR21400. Accordingly, the U.S. Government retains a paid-up, nonexclusive, irrevocable, worldwide license to publish or reproduce the published form of this contribution, prepare derivative works, distribute copies to the public, and perform publicly and display publicly, or allow others to do so, for U.S. Government purposes. 


\section{DISCLAIMER}

Portions of this document may be illegible in electronic image products. Images are produced from the best available original document. 


\title{
SHAKE TABLE TESTING OF STRUCTURAL CLAY TILE INFILLED FRAMES
}

\author{
by Richard M. Bennett ${ }^{1}$, Joele J. Fowler ${ }^{2}$, Roger D. Flanagan ${ }^{3}$
}

\begin{abstract}
Two steel frames with structural clay tile infills were tested under simulated seismic loads in both the out-of-plane and in-plane direction. Out-of-plane testing showed that infill panels separate from their bounding frame, and respond at their own natural frequency during a seismic excitation. Due to arching, the panels remain stable. In-plane seismic testing showed similar behavior patterns to previous static testing. The natural frequency was adequately predicted using a piecewise linear equivalent strut analytical method. The structure was then subjected to over one thousand cycles of loading using a sine sweep before failure.
\end{abstract}

KEYWORDS: Infills, In-Plane Behavior, Out-of-plane Behavior, Shake Table Testing, Structural Clay Tile

1 Professor of Civil and Environmental Engineering, The University of Tennessee, Knoxville, TN 37996-2010, USA

2 Carpenter Wright Engineers, P.L.L.C., Knoxville, TN 37923, USA

3 Manager, Advanced Technology Department, Lockheed Martin, Oak Ridge, TN 37831, USA 


\section{INTRODUCTION}

Infill construction is quite popular, particularly in the low to moderate seismic zones of the eastern/central United States. Infill walls may have both beneficial and detrimental affects on the structural behavior under seismic loading. Infill walls increase the stiffness of a building and thus the seismic force, shift the structure's center of stiffness and affect the forces in the framing possibly causing premature failure of frame members. Infills can also have a beneficial effect on the structural behavior. They serve to increase the stiffness of flexible frame buildings, and provide a redundant load path for both the horizontal and vertical loads.

Many buildings were constructed using clay tile masonry in the early part of the century, and extending into the World War II era. Although scattered throughout the United States, clay tile was extensively used in the high seismic regions of San Francisco and Los Angeles. An extensive static testing program on clay tile infills was recently completed (Flanagan, 1994). This paper reports the results of dynamic shake table testing.

\section{Test Set-up}

A one-story, single bay system was constructed with two structural clay tile infilled steel frames spaced approximately 9' apart. An 8" concrete roof slab was bolted to the top of the steel frames for mass, and a truss bracing system is connected between the two frames for added stiffness and strength. The steel frame consisted of W10x 30 columns and a W12x40 beam connected to form a nominal 8 ' high by 11 ' long wall. The beam to column connections were framed connections using double clip angles. The columns and beams were oriented so their strong axis resists in-plane motion. A three dimensional view of the test set-up for out-of-plane testing is shown in Figure 1.

The masonry infill panels were constru

cted using $12^{\prime \prime} \times 12^{\prime \prime} \times 8^{\prime \prime}$ structural clay tile. The walls were constructed using single wythe construction with a running bond. The tile were laid with the cores being horizontal with approximately $1 / 2$ " head joints and $1 / 2$ " bed joints using Type $N$ mortar. The infill was bonded to the web of the columns and the bottom flange of the beam by snugly packed full mortar joints between the steel and masonry. There was no reinforcement placed in the masonry. Testing was performed on 2'x 4'x 8" clay tile prisms (Jones and Butala 1994). The gross compressive strengths were $0.72 \mathrm{ksi}$ for the load perpendicular to the bed joint, and $1.02 \mathrm{ksi}$ for the load parallel to the bed joint.

The specimen was tested on the United States Army Construction Engineering Research Laboratories (USACERL) biaxial shake table. The specimen was first tested such that the infills were subjected to out-of-plane motion. The entire specimen was then rotated so that the infills were subjected to in-plane motion. Details of the testing are in Gamble (1993) and Fowler (1994). 


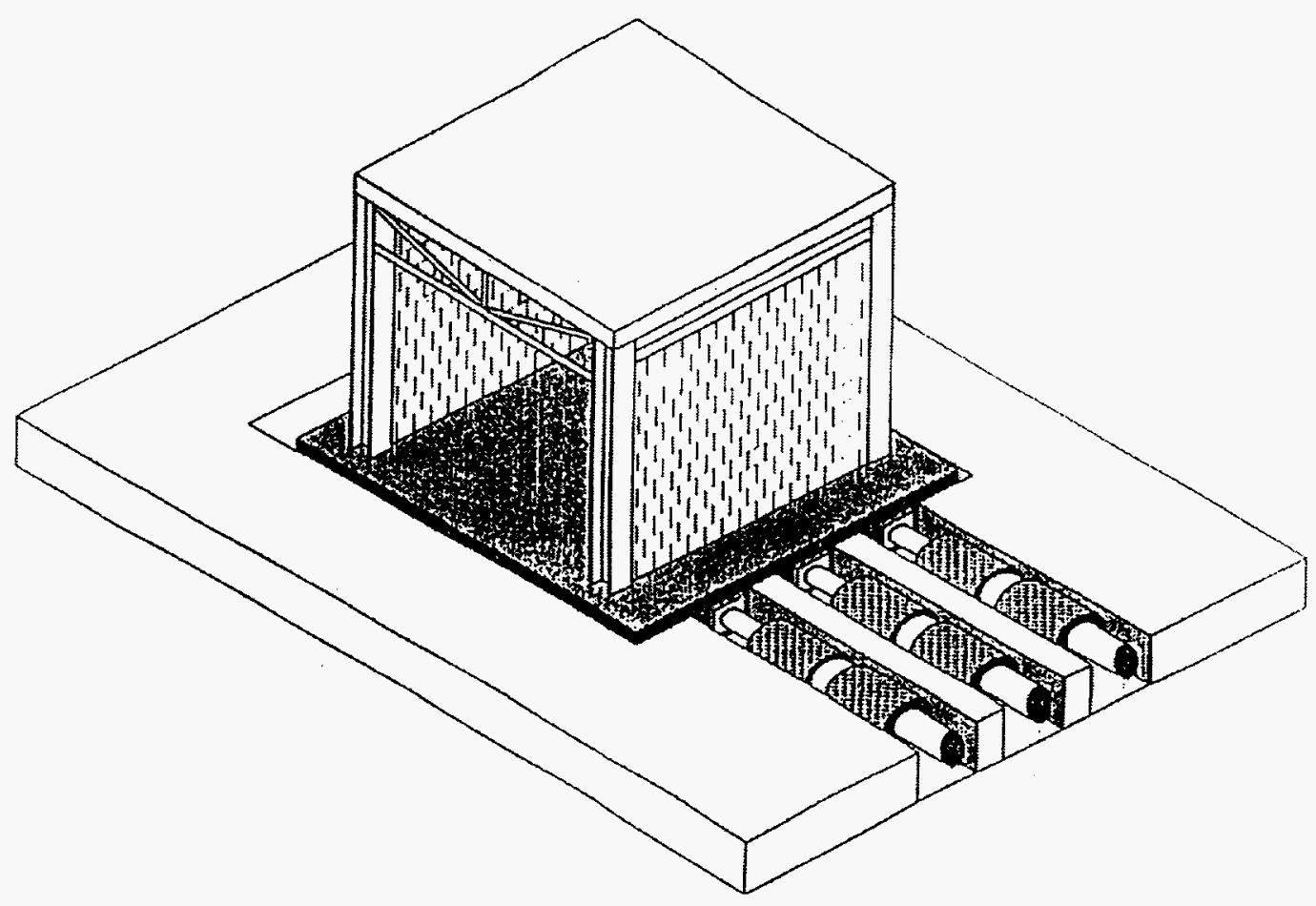

Figure 1: Three dimensional view of test setup (Gamble, 1993)

\section{OUT-OF-PLANE TESTING}

The structure was subjected to an artificially generated earthquake record that was representative of Oak Ridge, Tennessee. Peak acceleration for this record was $0.19 \mathrm{~g}$, with the strong motion lasting approximately ten seconds. The displacement record was programmed into the biaxial shake table and, in turn, used to excite the structure. The acceleration time history was used to calculate a acceleration response spectra for the system. Figure 2 shows the response spectra based on the actual table motion. The structure was actually subjected to three different loadings, these being at 1,2 and 4 times the full scale value of the time history displacements.

Figure 3 shows the acceleration data between 2.5 seconds and 3.3 seconds for the third seismic test ( $4 \mathrm{x}$ full scale). The figure shows the amplification of motion in the structure. In all the seismic tests, there was an amplification of approximately three in the wall panel, and approximately 2.5 in the top concrete slab. 


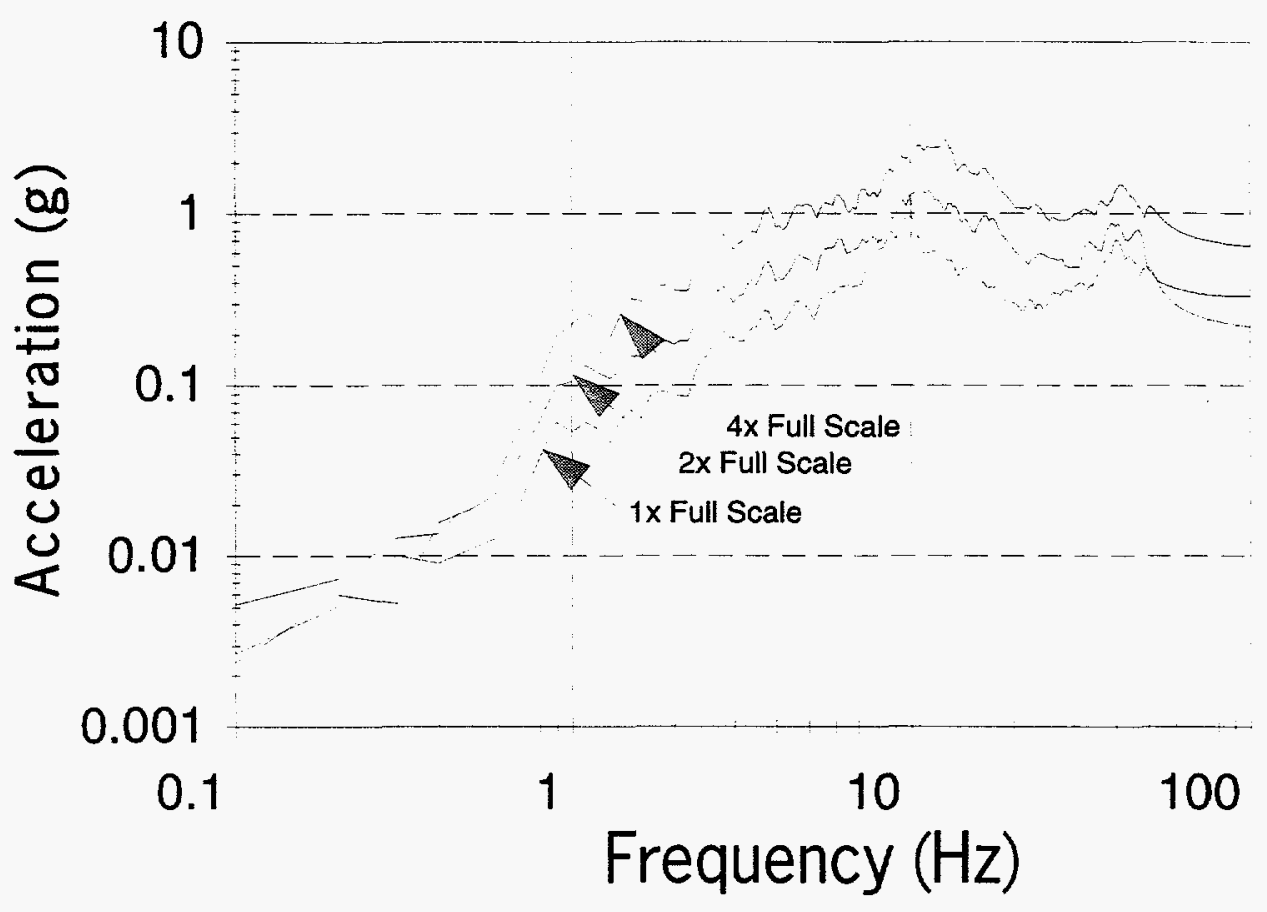

Figure 2: Out-of-plane acceleration response spectra

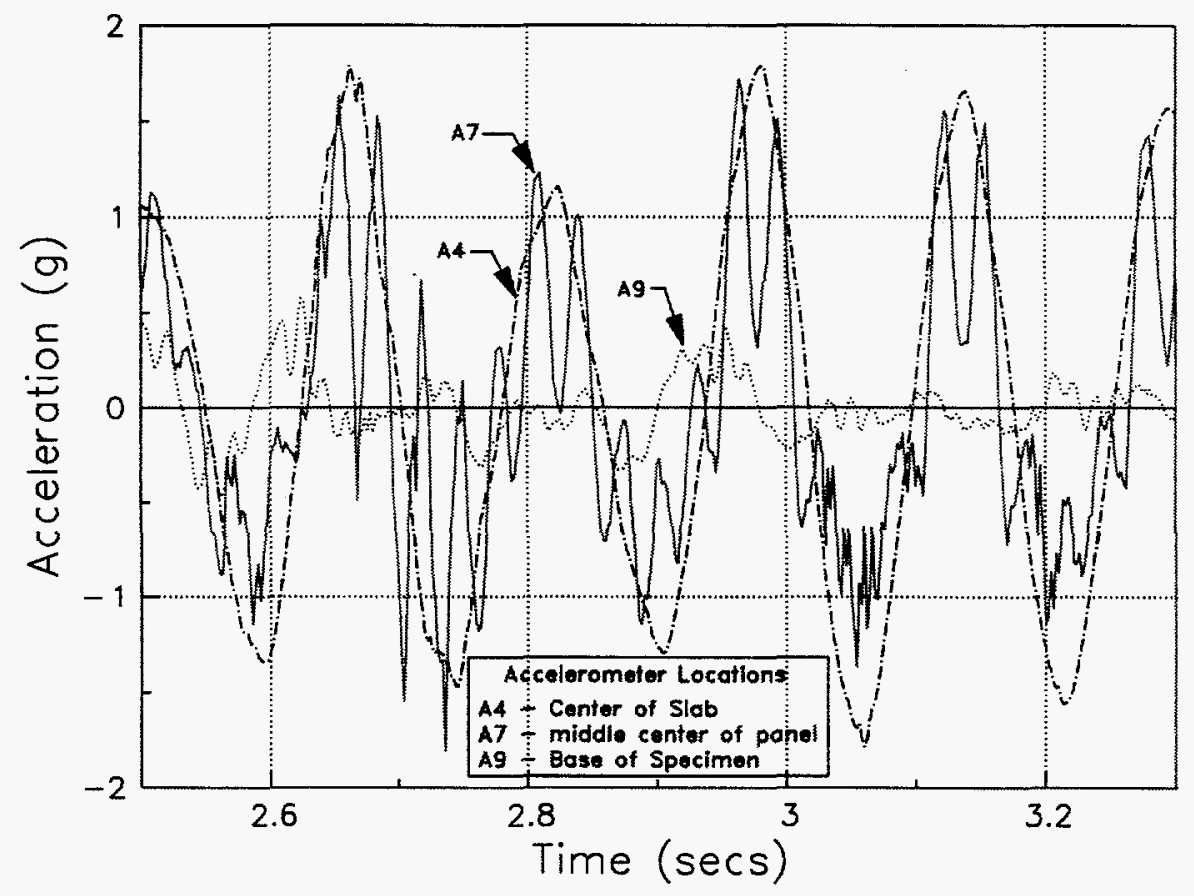

Figure 3: Accelerometer readings from the third seismic test 
Figure 3 also indicates that the infill wall and the top slab were responding at different frequencies. This is more clearly seen in Figure 4, which is a plot of the transform functions between the slab base and the top slab, frame, and wall panel. The top slab and frame are responding at a frequency of 6.4 $\mathrm{Hz}$. The infill wall panel was partially responding at the $6.4 \mathrm{~Hz}$ frequency, but the primary peak was at $31.7 \mathrm{~Hz}$.

Figure 5 shows the maximum deformed shape of the columns and infill wall panel. The "kink" near the top of the columns is due to the truss framing in at this point. It is clear from this that the infill and the frame were moving separately. This was further confirmed from relative displacement measurements between the wall and the frame. The largest relative displacements were by far near the middle of the panel, but even these were small ( 0.058 inches for the third seismic test).

Based on the data, it is clear that the bond between the infill and the frame was broken. The bounding frame and the infill were responding separately, each at their own natural frequency. Infills subjected to out-of-plane earthquake motions thus are not expected to follow the frame motions throughout the height of the infill. However, the infill panel did remain stable, and there were no signs of any "walking" or loss of stability of the panel during the tests. Even during the third tests (peak acceleration of $0.76 \mathrm{~g}$ ), the panel remained stable. This is due to the arching of the panel. Geometrically, the panel is confined in the panel. Thus, although the infill panel responds at a different frequency from the frame, it is still believed that arching controls the actual capacity. Arching can give significant capacity to infills, generally on the order of several $\mathrm{g}$ (Gabrielsen and Kaplan, 1977; Mander et al, 1994).

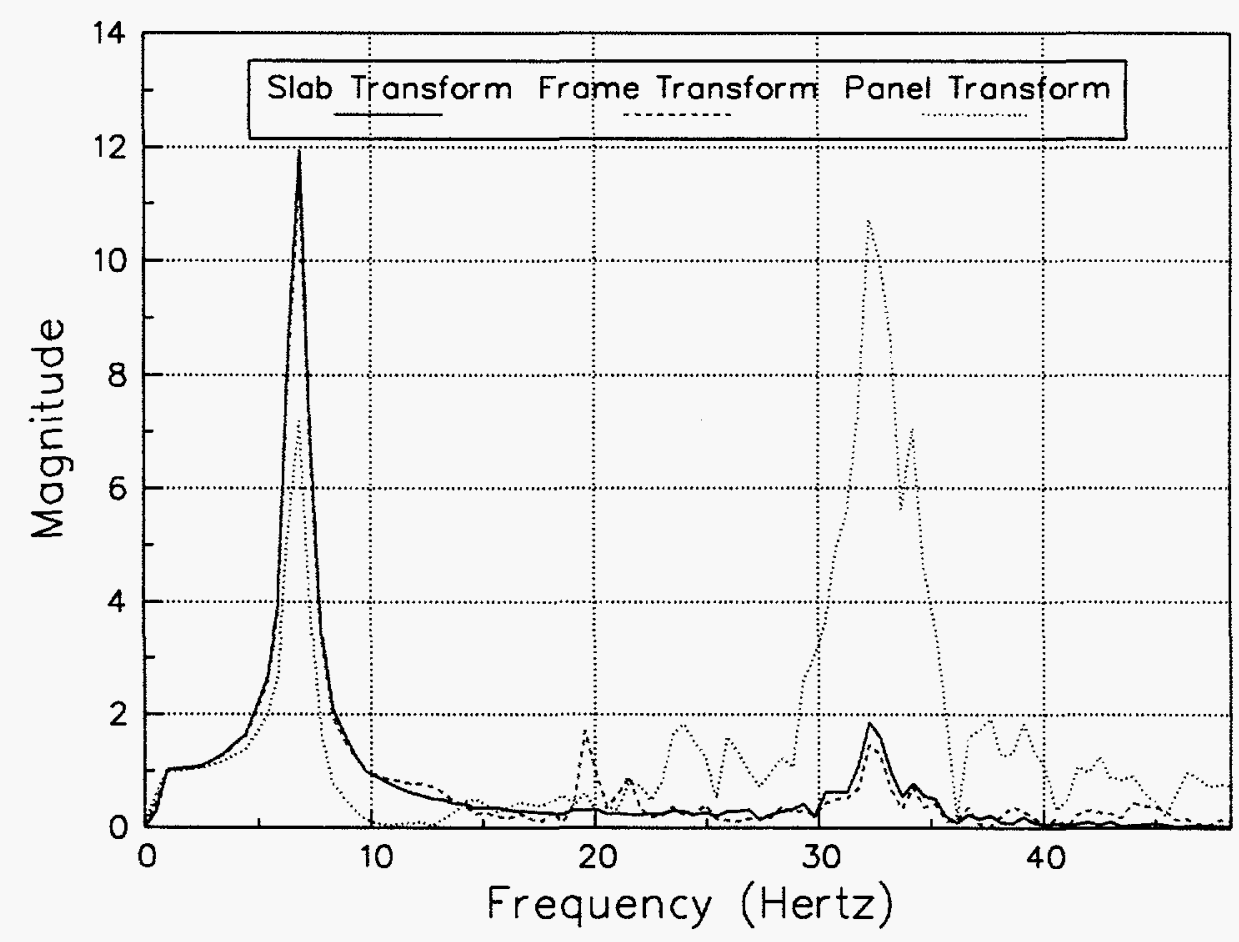

Figure 4: Transform functions from the third seismic test 


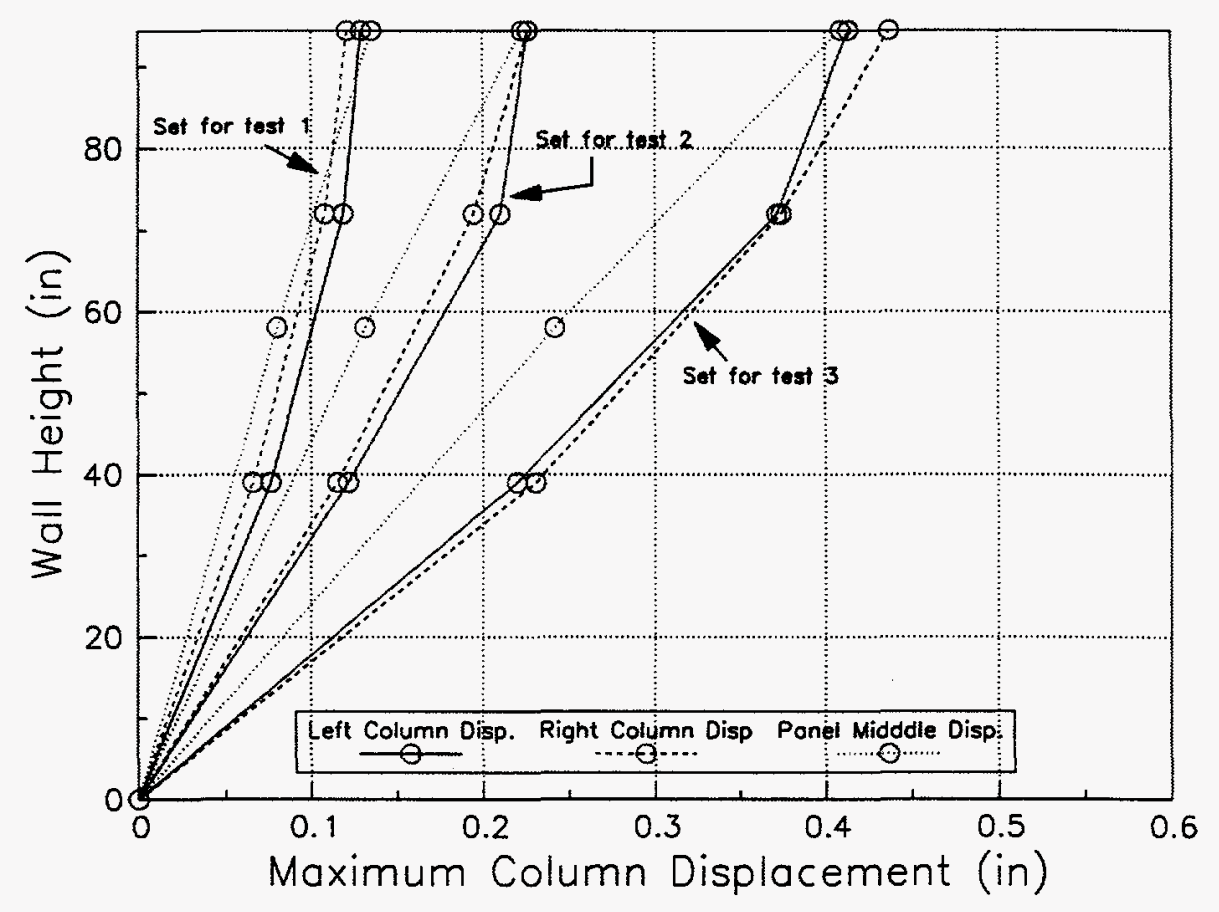

Figure 5: Maximum deformed shape of columns and panel

\section{IN-PLANE SEISMIC TESTING}

After completion of the out-of-plane tests, the specimen was rotated $90^{\circ}$ on the shake table so that the infill walls could be loaded in the in-plane direction. Six seismic tests were performed with the structure oriented in the in-plane direction using the same site specific time history record that was used for the out-of-plane tests. These tests were performed at 1,2, 4, 8, 12 and 16 times the full scale time history record. Seven low level random vibration white noise tests were performed to determine change in frequency of the structure as the testing progressed. A white noise test was performed at the beginning, and then following each seismic test. After completion of the tests, there was little damage to the structure. Some diagonal cracking through the mortar joints was noticed, but there were no tile failures.

The results of the in-plane testing were compared to previous static in-plane testing of similar panels (Barclay, 1993; Flanagan, 1994). For comparison, a "load"-deflection curve was developed, where the "load" for the dynamic testing was obtained as the lumped mass at the top of the structure multiplied by the acceleration recorded on the top concrete slab. Load-deflection loops for the maximum deformations in each test are shown in Figure 6. Figure 7 compares the load-deflection loop for the last seismic test (16x full scale) to that obtained from static testing.

Peak loads in the dynamic testing and static testing were similar, although there was much more damage to the infill at this point in the static testing. The ultimate load from the dynamic tests was expected to be a little higher since prism testing and unit block tile tests had shown that the block 


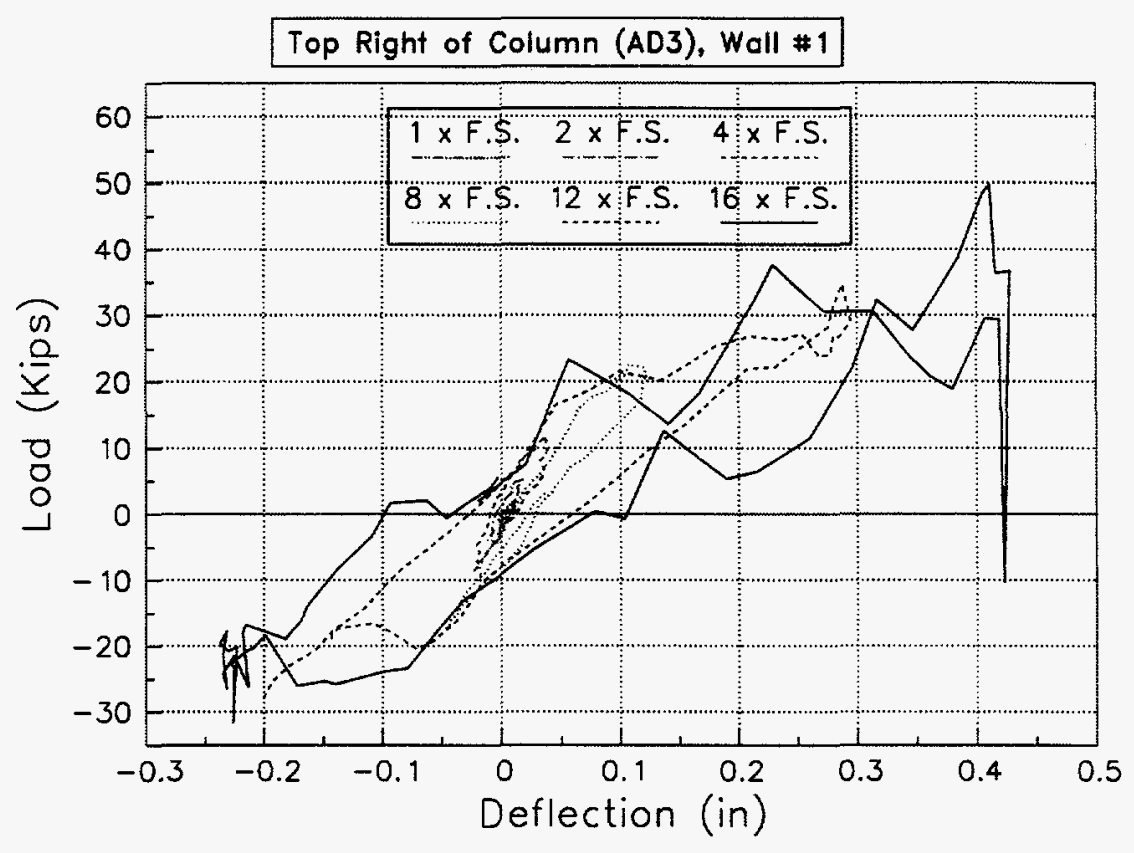

Figure 6: Load-deflection curve for seismic testing

used for the dynamic testing was a little stronger than those used in the static testing. The characteristic pinching of infill behavior was not as prevalent in the dynamic testing. Perhaps it would be more pronounced at higher excitation levels, or perhaps the vertical load from the top slab is causing a stiffer behavior.

Other aspects of the specimen behavior were similar to the static tests. Longitudinal strains along the diagonal reached a maximum of 0.00135 , compared to longitudinal strains in the static test of 0.00145 (Barclay, 1993). These were similar to strains recorded at failure in prism compression tests (Boyd, 1993). Little vertical or horizontal strain was observed in the panel during the first four seismic tests. Apparently there had been little to no cracking and the panel was responding elastically. In the last two seismic tests, the strain in the panels was increasing during both the compressive and tension cycles in a way similar to what was observed in the static test results. Due to significant cracking and panel degradation, the panel was expanding both laterally and longitudinally within the frame during loading.

Column axial forces were also similar to that observed in static testing. A tension force was developed in the "windward" column almost as high as the load taken by the structure. This supports the common idealization in which the infill is considered as an equivalent strut bracing the frame. Interestingly, a tension force of about one-third that in the "windward" column was developed in the top of the "leeward" column (this was also observed in the static testing). As the loads increase during the cycle, high lateral strains develop normal to the compression strut causing an upward force at the column and beam interfaces, resulting in a tensile force in the top of the column. 


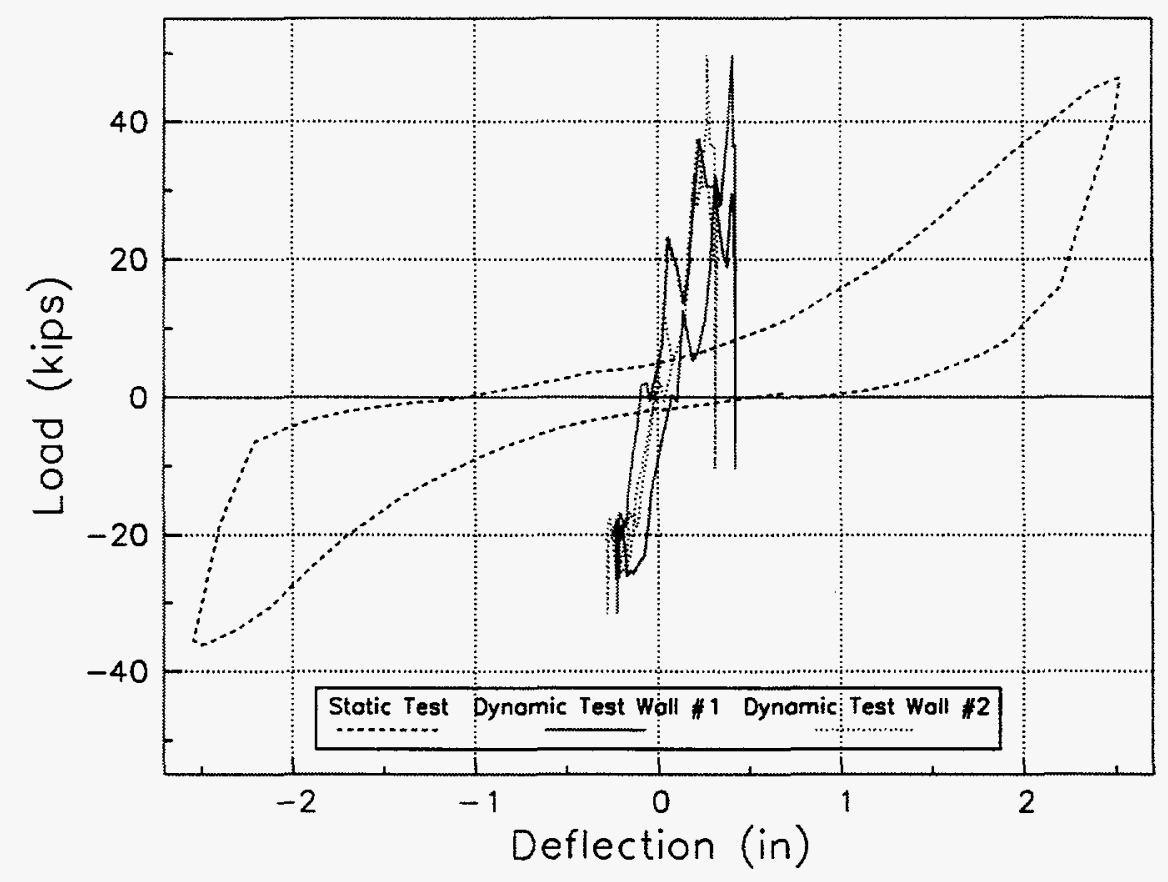

Figure 7: Static and dynamic load-deflection curve overplots

A high peak acceleration of approximately $13 \mathrm{~g}$ was noticed in the columns during the last seismic test $(16 \mathrm{x}$ full scale, peak ground acceleration of $3 \mathrm{~g})$. The peak acceleration in the infill was only about $60 \%$ of that of the column. A peak acceleration of approximately $6 \mathrm{~g}$ was noticed in the top slab, or an amplification of approximately 2 . Apparently the high peak accelerations in the column were due to the impact of the infill racking against the column after interface cracking. Due to the short duration impulse nature of the racking, these accelerations are not necessarily representative of actual column forces.

Table 1 shows the fundamental frequency of the structure obtained using a frequency transfer function on the response during the seismic tests and the low-level white noise tests. There is a noticeable difference between the two frequencies, particularly at the higher levels of excitation. This indicates the nonlinear nature of the response of infills. The implications are two-fold. First, low-level tests do not necessarily give an accurate picture of the natural frequency of an infill structure. Second, the stiffness of the structure is a function of the excitation level. Any analysis technique, such as using an equivalent strut, needs to account for this nonlinear behavior.

The observed natural frequency was compared to the predicted natural frequency using a piecewise linear strut formulation that had been developed based on static testing (Flanagan et al, 1994). The width of the equivalent strut is a reciprocal function of a parameter $\mathrm{C}$, where the value of the parameter $\mathrm{C}$ is based on the deflection of the infill. For deflections similar to those seen in the white noise test, a value of $\mathrm{C}=5$ is recommended. Using this results in a calculated natural frequency of $12.3 \mathrm{~Hz}$, which is only slightly lower than that observed. Based on the observed deflections during the last seismic test, a value of $\mathrm{C}=11$ is recommended. This results in a calculated frequency of 8.8 
$\mathrm{Hz}$, which agrees very well with the observed value of $8.8 \mathrm{~Hz}$. Thus, the shake table tests validate the developed analytical model, and show the need for a nonlinear analysis.

Table 1: Results of frequency analysis

\begin{tabular}{||c|c|c|c||}
\hline \multicolumn{2}{|c|}{ Seismic Tests } & \multicolumn{2}{|c|}{ White Noise Test } \\
\hline Test & Natural Frequency $(\mathrm{Hz})$ & Test & Natural Frequency $(\mathrm{Hz})$ \\
\hline $1 \mathrm{x}$ & 16.6 & Before 1x & 16.0 \\
$2 \mathrm{x}$ & 15.1 & After $1 \mathrm{x}$ & 16.7 \\
$4 \mathrm{x}$ & 15.6 & After $2 \mathrm{x}$ & 15.8 \\
$8 \mathrm{x}$ & 13.2 & After $4 \mathrm{x}$ & 16.2 \\
$12 \mathrm{x}$ & 10.3 & After $8 \mathrm{x}$ & 15.0 \\
$16 \mathrm{x}$ & 8.8 & After 12x & 13.3 \\
- & - & After $16 \mathrm{x}$ & 14.3 \\
\hline
\end{tabular}

\section{SINE SWEEP TESTS}

After the out-of-plane and in-plane tests were completed, two in-plane sine sweep tests were performed on the structure. The first sine sweep test was performed at an amplitude of $1.0 \mathrm{~g}$; the frequency started at 10 hertz and was increased up to 20 hertz. After the first sine sweep test was performed, the structure had not failed; hence, the second sine sweep test was performed. This test had an amplitude of $3.0 \mathrm{~g}$, and the frequency started at $15 \mathrm{~Hz}$ and was decreased down to $5 \mathrm{~Hz}$. The test was stopped at approximately $12.7 \mathrm{~Hz}$ when several tile failed and fell from the upper course of the wall. The sine sweep tests subjected the structure to a large number of loadings. Eight hundred fifty cycles of loading were performed on the structure during the $1.0 \mathrm{~g}$ sine sweep test and three hundred twenty cycles were performed during the $3.0 \mathrm{~g}$ sine sweep test. This greatly exceeds what would be expected in a typical seismic event. The loading could have significantly affected the characteristics of the structure and may have caused a "fatigue" type failure.

The sine sweep tests were conducted to excite the structure at its natural frequency. Based on the low level white noise tests, the natural frequency was erroneously thought to be in the $10-20 \mathrm{~Hz}$ range. Actually, the structure's natural frequency was lower than this, and the structure was being excited at a frequency greater than its natural frequency during the first sine seep test. The amplification of the ground motion was approximately 2.2 at the beginning of the test. This decreased quickly, and the amplification was approximately 1.2 for the remainder of the test. The "load" on the structure at the beginning of the test was $22 \mathrm{kips}$, and dropped to $9.5 \mathrm{kips}$.

In an attempt to find the natural frequency, the second sine sweep test was started at $15 \mathrm{~Hz}$, and the frequency gradually decreased. The lab technician stopped the test when tile began to fall out, but the natural frequency was not yet reached. Based on observations from the static testing, the infill still had significant capacity, and could have withstood further shaking. There was essentially no amplification of the ground motion in this test, since the excitation was significantly above the natural frequency. The "load" during the $3 \mathrm{~g}$ sine sweep test was $38 \mathrm{kips}$. Thus, the structure was 
subjected to over 300 cycles of loading at approximately $80 \%$ of the static panel capacity. This far exceeds the loading that would be expected from any realistic seismic event.

\section{CONCLUSIONS}

Out-of-plane testing showed that infill panels do separate from their bounding frame, and respond at their own natural frequency during a seismic excitation. Due to arching, the panels remain stable. Infill panels generally perform quite well in the out-of-plane direction.

In-plane seismic testing showed similar behavior patterns to previous static testing. The natural frequency was adequately predicted using an equivalent strut analytical method. Nonlinear, or piecewise linear, methods are necessary as the strut stiffness degrades with increasing deflection. As evidenced by the sine sweep tests, infills are able to withstand significant shaking at near the ultimate capacity prior to failure. Infills can be expected to enhance the seismic resistance of otherwise laterally weak structures.

\section{ACKNOWLEDGEMENTS}

The shake table testing was performed at the U.S. Army Construction Engineering Research Laboratories, Champaign, IL. The work was sponsored by the Center for Natural Phenomena Engineering, Martin Marietta Energy Systems, Inc., under contract with the U.S. Department of Energy. Part of the funding for the second author was from Oak Ridge Associated Universities.

\section{REFERENCES}

Barclay, G.A. 1993. "Behavior of Structural Clay Tile Infilled Steel Frames Subjected to In-Plane Loading." Thesis submitted in partial fulfillment of the requirements for the degree of Master of Science. he University of Tennessee, Knoxville, Tennessee.

Boyd, K.A. 1993. "Compressive Strength and Constitutive Behavior of Clay Tile Prisms." Thesis submitted in partial fulfillment of the requirements for the degree of Master of Science. University of Tennessee, Knoxville, Tennessee.

Flanagan, R.D. 1994. "Behavior of Structural Clay Tile Infilled Steel Frames." Dissertation submitted in partial fulfillment of the requirements of the degree of Doctor of Philosophy. The University of Tennessee, Knoxville, Tennessee.

Flanagan, R.D., Tenbus, M.A., and Bennett, R.M. 1994. "Seismic Evaluation of Industrial Facilities with Unreinforced Structural Clay Tile Infills." Fifth U.S. National Conference on Earthquake Engineering, EERI, 365-374. 
Fowler, J.J. 1994. "Analysis of Dynamic Testing Performed on Structural Clay Tile Infilled Frames." Thesis submitted in partial fulfillment of the requirements of the degree of Master of Science The University of Tennessee, Knoxville, Tennessee.

Gabrielsen, B.L., and Kaplan, K. 1977. "Arching in Masonry Walls Subjected to Out-ofPlane Forces." Earthquake Resistant Masonry Construction. NBS Building Science Series $106,283-313$.

Gamble, J.B. 1994. "Dynamic Out-of-Plane and In-Plane Testing of Full-Scale Hollow Clay Tile Infilled Frames." Test report prepared for Martin Marietta Energy Systems, Inc. U.S. Army Construction Engineering Research Laboratories. Champaign, Mlinois.

Jones, W.D. and Butala, M.B. 1994. "Testing of Hollow Clay Tile Masonry Prisms." Proceedings of the American Society of Civil Engineers Structures Congress. Atlanta, Georgia. Vol. 2, 1094-1099.

Mander, J.B., Aycardi, L.E. and Kim, D.K. 1994. "Physical and Analytical Modeling of Brick Infilled Steel Frames." Proceedings from the National Center For Earthquake Engineering Research Workshop on Seismic Response of Masonry Infills. Buffalo, New York. Technical Report NCEER-94-0004, pp. 1-21 to 1-26. 
Distribution:

R. M. Bennett

D. R. Denton

R. D. Flanagan

K. E. Fricke

R. J. Hunt

R. J. Kroon

A. K. Lee/DOE OSTI (2)

N. E. Stone

M. A. Tenbus

CAE Files

Y-12 Central Files 